\title{
Afval aangetroffen tijdens de jaarlijkse schelpdiermonitoring in de Waddenzee en Nederlandse kustzone in 2019
}

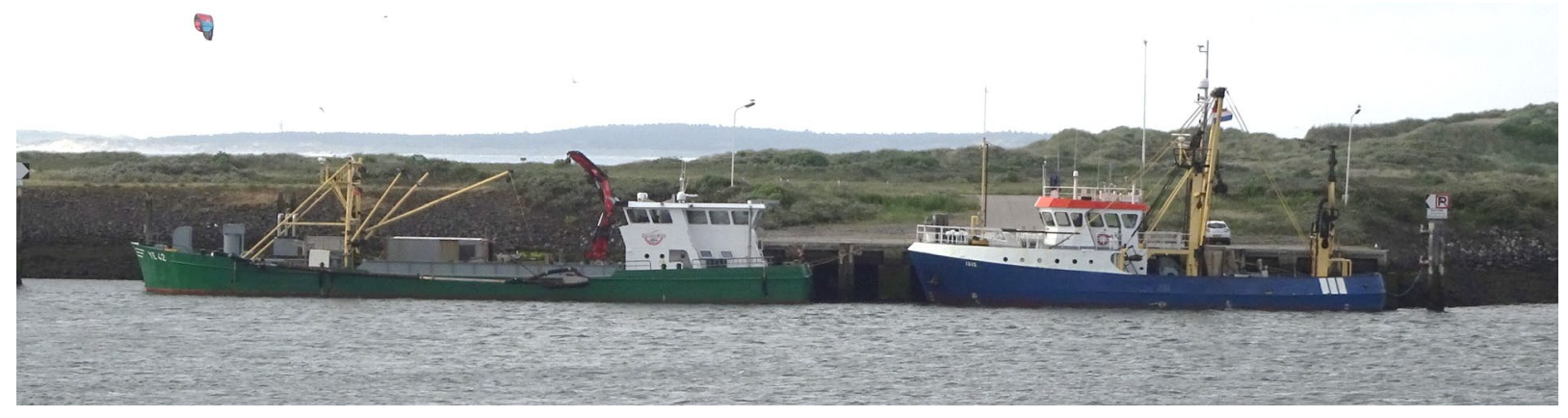

Dit onderzoek is uitgevoerd door Wageningen Marine Research in opdracht van en gefinancierd door het Ministerie van Landbouw, Natuur en Voedselkwaliteit, in het kader van het Beleidsondersteunend onderzoekthema 'Natuurinclusieve Visserij' (projectnummer BO-43-023.02-039), en door Rijkswaterstaat NoordNederland

Auteurs: Jetze van Zwol, Karin Troost

Wageningen Marine Research

Yerseke, december 2019 
Keywords: Waddenzee, Noordzee, schelpdiermonitoring, afval, containerramp, Zoë.

Opdrachtgever: $\quad$ Ministerie van LNV - t.a.v. Marjan Datema

Rijkswaterstaat Noord-Nederland - t.a.v. Jacco Doze

Projectnummer: BO-43-023.02-039

Dit rapport is gratis te downloaden van https://doi.org/10.18174/508324

Wageningen Marine Research verstrekt geen gedrukte exemplaren van rapporten.

Wageningen Marine Research is ISO 9001:2015 gecertificeerd.

Foto omslag: De twee onderzoekschepen YE 42 en RV Isis, Jetze van Zwol 2018

\section{(C) Wageningen Marine Research}

Wageningen Marine Research, instituut binnen de rechtspersoon Stichting

Wageningen Research, hierbij vertegenwoordigd door Dr. M.C.Th. Scholten, Algemeen directeur

KvK nr. 09098104,

WMR BTW nr. NL 8113.83.696.B16.

Code BIC/SWIFT address: RABONL2U

IBAN code: NL 73 RABO 0373599285
Wageningen Marine Research aanvaardt geen aansprakelijkheid voor gevolgschade, noch voor schade welke voortvloeit uit toepassingen van de resultaten van werkzaamheden of andere gegevens verkregen van Wageningen Marine Research. Opdrachtgever vrijwaart Wageningen Marine Research van aanspraken van derden in verband met deze toepassing.

Alle rechten voorbehouden. Niets uit deze uitgave mag weergegeven en/of gepubliceerd worden, gefotokopieerd of op enige andere manier gebruikt worden zonder schriftelijke toestemming van de uitgever of auteur. 


\section{Inhoud}

Samenvatting

$1 \quad$ Aanleiding

$\begin{array}{llc}1.1 & \text { Opdracht } & 6\end{array}$

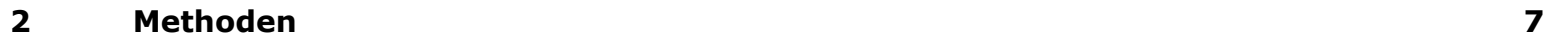

2.1 Schelpdiersurveys Waddenzee $\quad 8$

Sublitoraal mosselbestand $\quad 8$

Litorale mosselbanken $\quad 8$

Litorale schelpdierbestanden $\quad 8$

2.2 Schelpdiersurvey Noordzeekustzone $\quad 9$

$\begin{array}{ll}2.3 & \text { Verzameling en registratie van afval } \\ \end{array}$

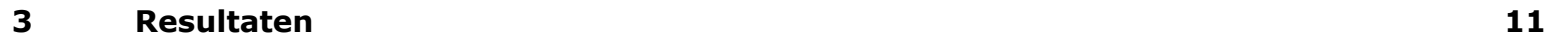

3.1 Noordzee 11

3.2 Waddenzee $\quad 13$

$4 \quad$ Conclusies en discussie $\quad 16$

$\begin{array}{lc}\text { Conclusie } & 16\end{array}$

Discussie $\quad 16$

$\begin{array}{llr}5 & \text { Kwaliteitsborging } & 17\end{array}$

$\begin{array}{lr}\text { Literatuur } & 18\end{array}$

$\begin{array}{lr}\text { Verantwoording } & 19\end{array}$

$\begin{array}{llr}\text { Bijlage } 1 & \text { Overzichtskaarten Noordzee } & 20\end{array}$

$\begin{array}{llr}\text { Bijlage } 2 & \text { Overzichtskaarten Waddenzee } & \mathbf{2 1}\end{array}$

$\begin{array}{llr}\text { Bijlage } 3 & \text { Invoer overzicht IBTS } & 22\end{array}$ 


\section{Samenvatting}

In januari 2019 zijn tijdens een storm zo'n 345 zeecontainers overboord geslagen vanaf containerschip 'MSC Zoë'. Dit gebeurde in de vaarroute langs de Nederlandse Waddeneilanden in de Noordzee. Een deel van de containers is aangespoeld op de eilanden maar de meeste zijn gezonken. Door de val vanaf het schip zijn containers beschadigd en opengescheurd. Hierbij is veel lading in zee gekomen en als afval naar de eilanden, Waddenzee en de zeebodem verdwenen. De aangespoelde lading is veelal opgeruimd net als de achter gebleven container (resten) op de bodem. Omdat er veel lading achter gebleven is in het marine milieu wordt er verwacht dat dit terug te vinden is tijdens de diverse kust bemonsteringen welke uitgevoerd worden door Wageningen Marine Research (WMR).

WMR voert jaarlijkse WOT-schelpdierinventarisaties uit in de Noordzeekustzone en de Waddenzee. Deze surveys bestrijken een groot gebied rond de locatie van het incident en het gebied waar mogelijk afval terecht gekomen is. Deze surveys zijn geselecteerd voor de monitoring van afval dat mogelijk afkomstig zou kunnen zijn uit de lading van de MSC Zoë. Op de Noordzee wordt gebruik gemaakt van een bodemschaaf waarmee op 983 locaties een 'trek' van 150 meter gedaan wordt. Op de Waddenzee wordt de bemonstering uitgevoerd met een zuigkor (gesleept), stempelkor en oesterhapper (vast oppervlakte). Door middel van deze tuigen worden 1360 geselecteerde locaties bemonsterd. Daarnaast worden oester- en mosselbanken in kaart gebracht doormiddel van een survey 'te voet' waarbij afval verzameld kon worden er is minstens 630 kilometer afgelegd.

Op de Noordzee is op 56 locaties afval gevonden, waarschijnlijk is geen enkel soort materiaal afkomstig van de lading van de MSC Zoë. Op de Waddenzee is op 43 locaties afval gevonden tijdens de bemonstering, daarnaast is op 7 verschillende locaties afval aangetroffen tijdens het 'lopen'. Tijdens de bemonsteringen vanaf het schip is geen materiaal aangetroffen wat gekoppeld kan worden aan de lading van de MSC Zoë. Te voet zijn enkele voorwerpen aangetroffen die waarschijnlijk afkomstig zijn uit de lading van de MSC Zoë.

Na de uitvoering van de surveys en analyse van de resultaten lijkt het er op dat de type tuigages welke gebruikt worden voor de bodem bemonstering alleen een klein formaat afval bevatten. Na het incident met de MSC Zoë zijn vooral grotere voorwerpen aangespoeld, die dus in de gebruikte tuigages niet worden teruggevonden. Mogelijk achtergebleven afval lijkt het makkelijkst waar te nemen wanneer de survey te voet plaatsvindt. 


\section{$1 \quad$ Aanleiding}

Begin januari is het containerschip MSC Zoë tijdens een storm 342 containers verloren. Het schip bevond zich in de scheepvaartroute ten noorden van de Waddeneilanden en was op weg naar Bremerhaven (Duitsland). De route bevindt zich relatief dicht bij de Waddeneilanden en de daar achter liggende Waddenzee. Enkele containers spoelden intact aan op de kust maar de meeste zijn op de zeebodem terechtgekomen met onbekende schade. De inhoud van een groot aantal containers is hierbij vrijgekomen en op drift geraakt.

De containers zijn in het gebied tussen Vlieland en het Duitse Borkum gevonden in de scheepvaartroute en in het gebied ten zuiden hier van (zie figuur 1 ter illustratie). Gevreesd werd dat de verspreiding van artikelen uit de containers, verder 'afval' genoemd, in de Noordzee en Waddenzee tot ecologische problemen zou leiden. Om de omvang van de vervuiling in kaart te brengen hebben daarom het ministerie van LNV en Rijkswaterstaat opdracht gegeven om tijdens bestaande surveys zoveel mogelijk het uit de verloren containers afkomstige afval te registreren en verzamelen.

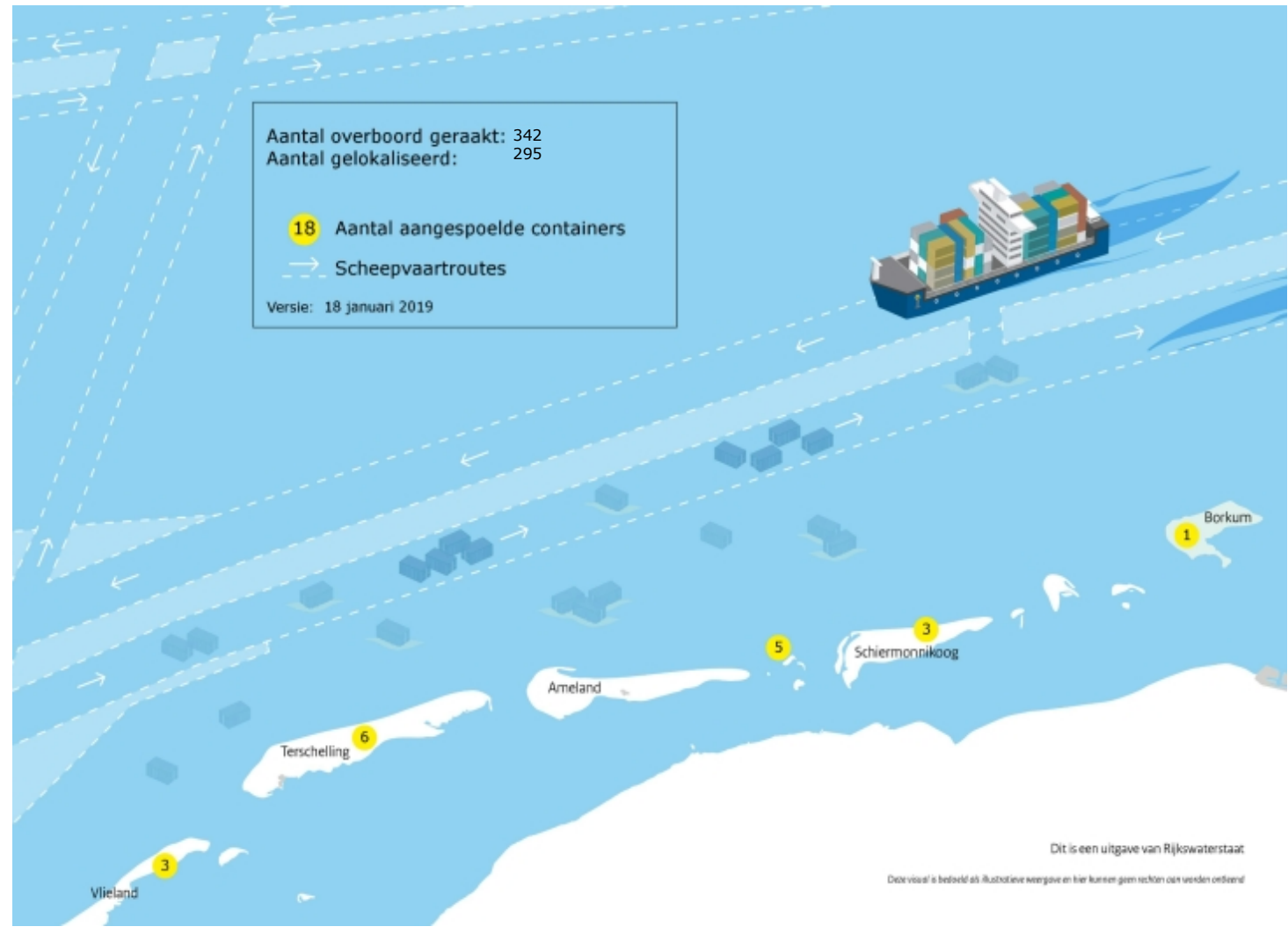

Figuur 1. Illustratie van situatie verloren containers t.o.v. route en Waddeneilanden (Rijkswaterstaat, aangepast aan actualiteit). 


\section{$1.1 \quad$ Opdracht}

Het ministerie van LNV heeft opdracht gegeven aan Wageningen Marine Research om tijdens lopende surveys en onderzoeksprojecten in de Waddenzee zoveel mogelijk het aangetroffen afval te registreren (Beleidsondersteunend Onderzoek: BO-43-023.02-039). Deze lopende surveys zijn zeer divers en lopen uiteen van onderzoek naar microplastics in mosselen tot reguliere inventarisaties van schelpdieren en vissen tot de maaginhoud van zeezoogdieren. Aanvullend heeft Rijkswaterstaat eenzelfde soort opdracht gegeven voor monitoring in de Noordzee.

Voorliggende rapport behandelt het aangetroffen afval tijdens de reguliere schelpdierinventarisaties in de Waddenzee (in opdracht van het ministerie van LNV) en de kustzone van de Noordzee (in opdracht van Rijkswaterstaat). Het doel was om alle aangetroffen soorten afval te registreren en de verspreiding en hoeveelheden daarvan inzichtelijk te maken in kaarten en tabellen. Voor zover mogelijk moest van de aangetroffen afvalitems ingeschat worden of deze afkomstig zijn uit de verloren containers. 


\section{Methoden}

De onderzochte gebieden zijn de Waddenzee en de gehele Nederlandse kustzone (Noordzee). In deze gebieden is tijdens de reguliere schelpdiersurveys al het aangetroffen afval geregistreerd. In tabel 1 wordt een overzicht gegeven van de betreffende surveys. Hieronder wordt iedere survey beknopt beschreven. Voor een meer uitgebreide uitleg wordt verwezen naar de betreffende surveyrapportages (zie referenties in 2.1 en 2.2 ).

Tabel 1. Overzicht van de reguliere schelpdiersurveys gebruikt voor afval registratie.

\begin{tabular}{lll}
\hline Survey & Gebied & Periode 2019 \\
\hline Sublitoraal mosselbestand & Waddenzee & Wk $11 \mathrm{t} / \mathrm{m} 14$ \\
Litorale mosselbanken & Waddenzee & Wk $15 \mathrm{t} / \mathrm{m} 17$ \\
Litorale schelpdierbestanden & Waddenzee & Wk $18 \mathrm{t} / \mathrm{m} \mathrm{23}$ \\
Schelpdiersurvey Noordzeekustzone & Noordzee & Wk $14 \mathrm{t} / \mathrm{m} \mathrm{22}$
\end{tabular}

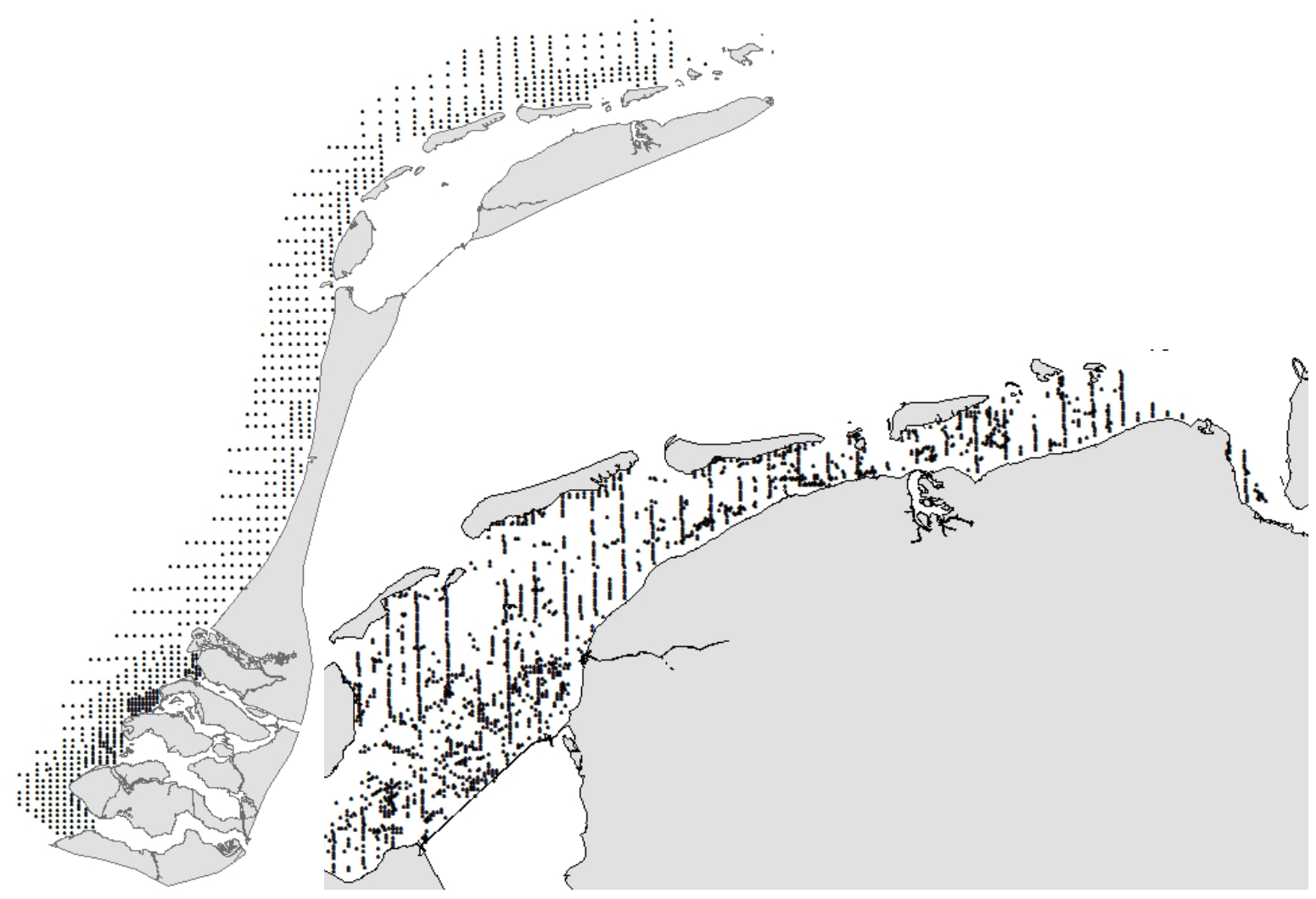

Figuur 2. Overzichtskaart met alle monsterpunten Noordzeekustzone (links) en Waddenzee (rechts) waar WOT schelpdierinventarisatie uitgevoerd zijn aangevuld met afval onderzoek.

In bovenstaande figuur 2 is een overzicht weergeven van alle bezochte locaties (punten) binnen de beschreven WOT schelpdierinventarisaties op de Noordzee en Waddenzee. Deze surveys bestrijken de gehele Waddenzee en de gehele Nederlandse kustzone en geven daarmee een goed beeld van de verspreiding van eventueel aangetroffen afval. 


\section{$2.1 \quad$ Schelpdiersurveys Waddenzee}

\section{Sublitoraal mosselbestand}

Sinds 1992 wordt jaarlijks is de periode maart-april het bestand aan mosselen in de Westelijke Waddenzee geschat welke permanent onderwater leven. Hiertoe worden tussen de 400 en 600 monsterpunten bemonsterd in de kombergingen Vliestroom en Marsdiep. De bemonstering wordt uitgevoerd met een zuigkor, en op locaties dieper dan 12 meter met een bodemschaaf. Beide monstertuigen snijden $7 \mathrm{~cm}$ diep door de bodem, over een breedte van respectievelijk 20 en $10 \mathrm{~cm}$, en over een lengte van ongeveer $150 \mathrm{~m}$. Dit levert per monsterpunt een bemonsterd oppervlak op van respectievelijk ongeveer 30 en $15 \mathrm{~m}^{2}$. De vangst wordt gezeefd over een maaswijdte van $5 \mathrm{~mm}$. Van monsters genomen met de zuigkor wordt standaard een deelmonster van $15 \%$ genomen, ongeacht het totale volume. Van monsters uit de bodemschaaf met een grotere omvang dan 6 liter wordt een deelmonster genomen van 6 liter precies. Voor verdere uitleg wordt verwezen naar het meest recente rapport (Van Stralen et al., 2019). Opdrachtgever voor deze survey is de Producentenorganisatie van de Nederlandse Mosselcultuur.

\section{Litorale mosselbanken}

Sinds 1995 wordt ieder voorjaar het areaal aan droogvallende mosselbanken (Mytilus edulis) en oesterbanken (Crassostrea gigas) in de Waddenzee ingeschat door de banken in het veld met een hand-held GPS in te meten. Dit gebeurt in de periode april-mei. Per laagwaterperiode worden 3-5 mensen op de plaat afgezet, zo dicht mogelijk bij de in te meten banken. Ieder loopt een afstand van ongeveer 100-3.000 meter tot de in te meten banken en loopt hier met de GPS in de hand omheen, de contouren markerend middels waypoints. Voor meer uitleg wordt verwezen naar het meest recente rapport (Van den Ende et al., 2018). Deze survey valt onder de Wettelijke Onderzoekstaken (WOT) op het gebied van visserij, en wordt uitgevoerd in opdracht van het Ministerie van LNV.

\section{Litorale schelpdierbestanden}

Sinds 1990 worden de bestanden aan kokkels, mosselen en Japanse oesters op de droogvallende platen van de Waddenzee geschat. Hiertoe worden in de periode april-juni ongeveer 1000 monsterpunten verspreid over de gehele Waddenzee bemonsterd. Er wordt gebruik gemaakt van drie monstertuigen welke allemaal een hapje uit de bodem nemen, met een bemonsterd oppervlak van 0,1 tot $0,4 \mathrm{~m}^{2}$, tot een diepte van $7 \mathrm{~cm}$. De monsters worden gezeefd over een maaswijdte van $5 \mathrm{~mm}$ waarna alle schelpdieren en andere soorten macrobenthos (zoals zeesterren en krabben) worden geteld en gewogen. Voor verdere uitleg wordt verwezen naar de meest recente rapporten (Van den Ende et al., 2018; Van Asch et al., 2019). Deze survey valt onder de Wettelijke Onderzoekstaken (WOT) op het gebied van visserij, en wordt uitgevoerd in opdracht van het Ministerie van LNV. 


\subsection{Schelpdiersurvey Noordzeekustzone}

De schelpdiersurvey op de Noordzee wordt door WMR uitgevoerd met RV Isis van de Rijksrederij. Er wordt bemonsterd met een bodemschaaf (Troost et al, 2018). Het monstertuig snijdt $7 \mathrm{~cm}$ diep door de bodem, over een breedte van $10 \mathrm{~cm}$ en over een lengte van ongeveer $150 \mathrm{~m}$. Dit levert per monsterpunt een bemonsterd oppervlak op van ongeveer $15 \mathrm{~m}^{2}$. De vangst wordt gezeefd over een maaswijdte van $5 \mathrm{~mm}$. Bij een monster groter dan \pm 8 liter wordt deze gedeeld tot een submonster van 6 liter, boven een vangst van 100 liter is dit submonster 12 liter. Voor verdere uitleg wordt verwezen naar het meest recente rapport (Perdon et al., 2018). De monsters worden gezeefd over een maaswijdte van $5 \mathrm{~mm}$ waarna alle schelpdieren en andere soorten macrobenthos (zoals zeesterren en krabben) worden geteld en gewogen. Deze survey valt onder de Wettelijke Onderzoekstaken (WOT) op het gebied van visserij, en wordt uitgevoerd in opdracht van het Ministerie van LNV. 


\subsection{Verzameling en registratie van afval}

Het verzamelen van afval is tijdens het inlopen van litorale mosselbanken anders uitgevoerd dan tijdens de overige drie surveys waarbij bodemmonsters zijn genomen. Tijdens het inlopen van litorale mosselbanken is alle afval welke werd aangetroffen in het loopspoor meegenomen en aan boord opgeslagen voorzien van een label met datum en locatie. Het loopspoor betreft de route vanaf het punt waar iemand is afgezet op de plaat tot aan de in te lopen mossel-/oesterbanken, de contouren daaromheen en de route naar waar men tenslotte weer is opgepikt. Er is niet gericht gezocht naar afval, de route ten behoeve van het inmeten van mossel- en oesterbanken is niet aangepast, en men heeft alleen meegenomen wat men zag liggen in het loopspoor. Artikelen die niet meegenomen zijn betreffen grotere artikelen welke duidelijk niet afkomstig waren van het containerschip (twee viskisten, deels in het slik en onder de zeepokken, en één Kliko container) en vispluis (wordt nader uitgelegd in de discussie; veelal verstrikt in de schelpdierbank, losse plukken zijn zoveel mogelijk meegenomen en aan boord in de afvalbak gedaan).

Tijdens de monsternames is alle afval aangetroffen in de monsters, dus na zeven over $5 \mathrm{~mm}$ en na het nemen van een eventueel submonster aan dek, geregistreerd volgens het IBTS protocol. De International Bottom Trawl Survey (IBTS) is een vissurvey waarbij een protocol wordt gevolgd om zwerfvuil bijvangst te monitoren. Om de registratie gelijkwaardig te behandelen, is protocol met bijbehorende categorieën ook toegepast binnen de WOT schelpdiersurveys. Het formulier met bijbehorende categorieën is opgenomen in bijlage 3 . 


\section{Resultaten}

De resultaten van het afval (o.a. plasticafval) onderzoek tijdens de genoemde schelpdiersurveys worden per gebied (Noordzee en Waddenzee) weergeven. Per gebied wordt eerst een kaart (figuur 4) weergeven met alle locaties waarop een 'afval-item' is aangetroffen. Daarna wordt in een tabel weergeven welke typen afval zijn aangetroffen met het totale aantal en het totale gewicht.

\subsection{Noordzee}

In de kustzone van de Noordzee is op 56 van de 983 bemonsterde locaties afval gevonden (figuur 4). Het meest aangetroffen type afval was vispluis (19 stuks), gevolgd door glasscherven (9 stuks). Het volledige overzicht wordt gegeven in tabel 2 . In bijlage 1 zijn twee kaarten met het aantal gevonden aantallen (eenheden) afval per locatie en het totale gewicht van afval in grammen per locatie weergeven.

Tabel 2 Aangetroffen soorten afval met aantallen en totaalgewicht in gram weergeven.

\begin{tabular}{l|ll}
\hline Voorwerp & Aantal & Totaalgewicht (g) \\
\hline Vispluis $^{* 1}$ & 19 & 3 \\
Glas & 9 & 94.3 \\
Touw & 6 & 1.8 \\
Folie & 4 & 1.8 \\
Draadje & 3 & 0.3 \\
Visdraad*2 & 3 & 0.4 \\
Verroest metaal & 2 & 42.7 \\
Tape & 2 & 7.2 \\
Stukje plastic dop & 1 & 0.7 \\
Hout & 1 & 88.4 \\
Opgedroogd verf op plastic & 1 & 18.9 \\
Onderkant plastic koffiebekertje & 1 & 0.3 \\
Stuk verfblik & 1 & 2 \\
Plastic & 1 & 0.1 \\
Zilverfolie & 1 & 0.3 \\
Stuk elastiek & 1 & 0.4 \\
Stuk filter (machinekamer) & 1 & 13.4 \\
\hline
\end{tabular}
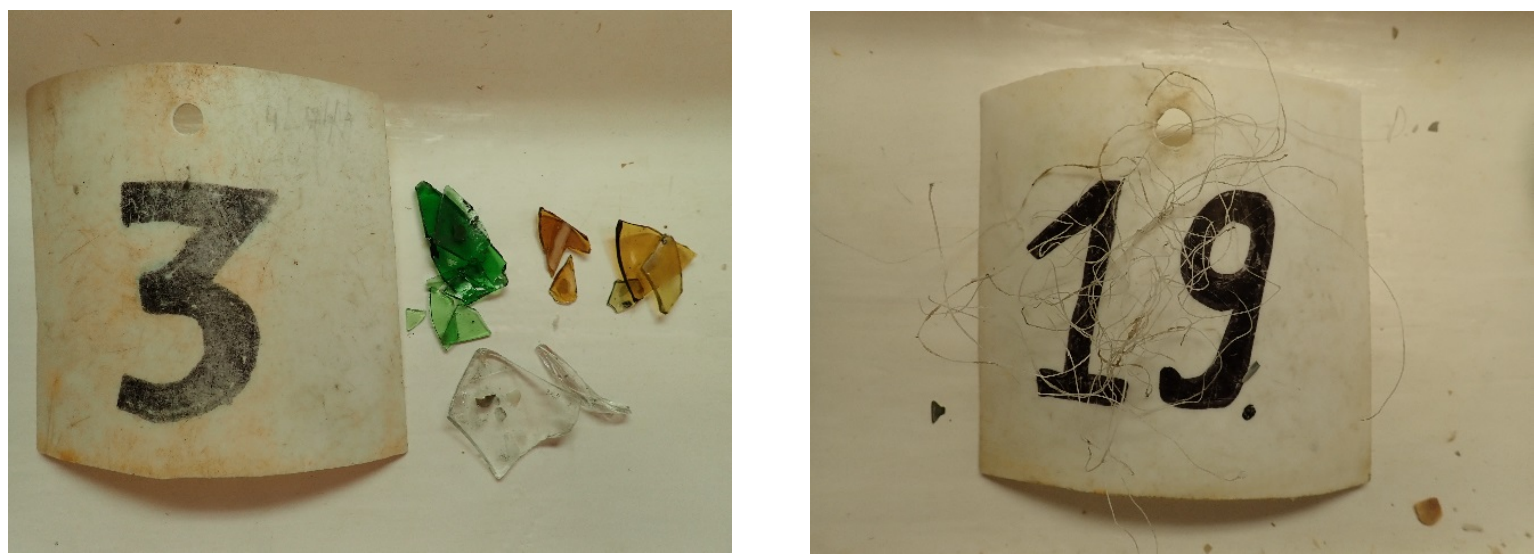

Figuur 3. Voorbeelden van aangetroffen afval. Links glasscherven in het 3de monster van de dag, Rechts visdraad in het 19de monster van de betreffende dag.

*1 - Vispluis: ook wel pluis genoemd, fel oranje of blauwe plastic draadjes die in trossen onder visnetten voor bodemvisserij hangen om deze te beschermen tegen slijtage. (Bron: www.vispluisvrij.nl)

*2 - Visdraad: Gekleurde of transparante plastic draad, afkomstig uit de sportvisserij. 


\section{Aangetroffen afval Noordzee kustzone}

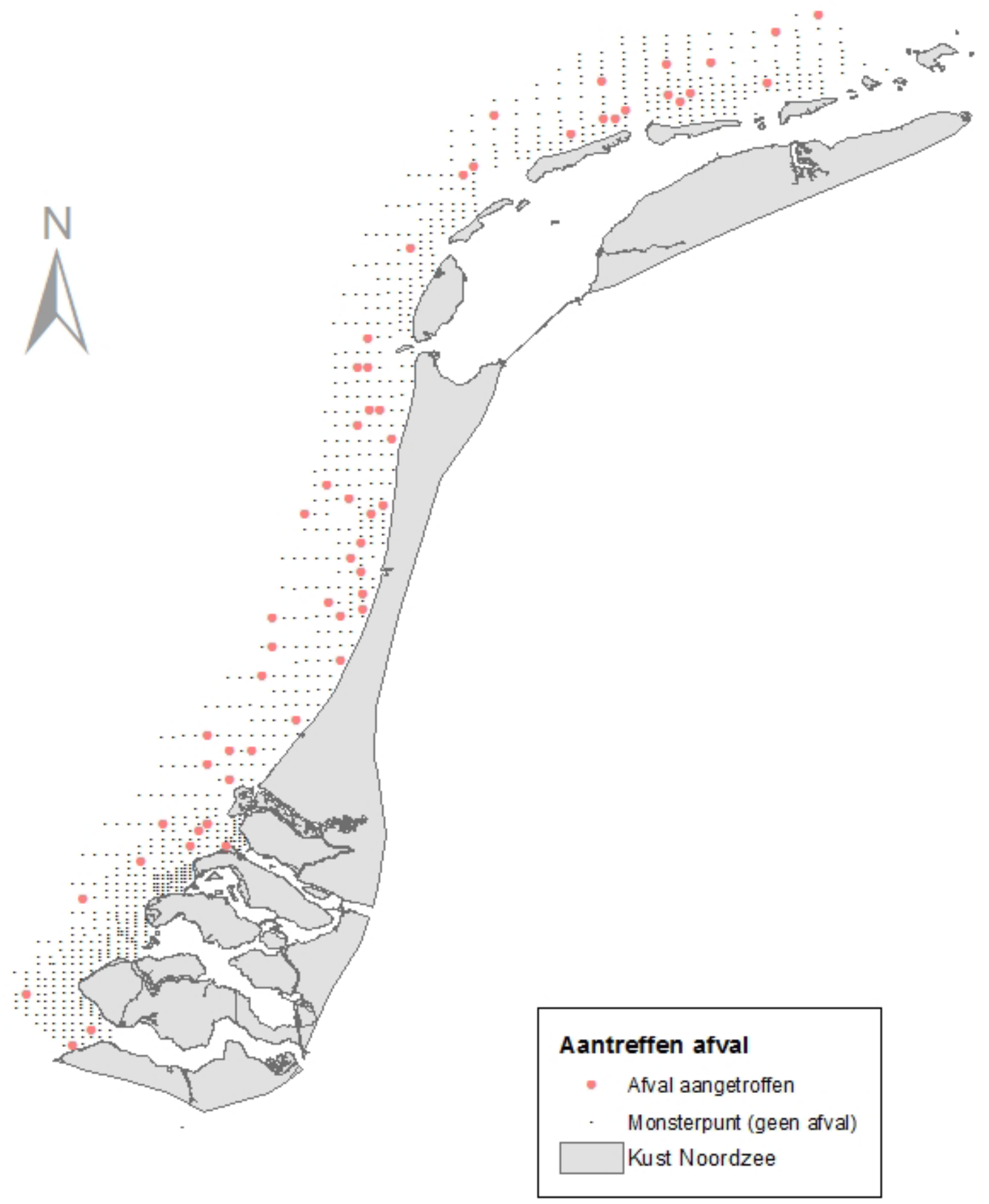

Figuur 4 Overzichtskaart aangetroffen afval tijdens de survey in de Noordzeekustzone 


\subsection{Waddenzee}

Voor de Waddenzee worden de resultaten uit de drie afzonderlijke surveys gecombineerd. Dit betreft afval dat is verzameld tijdens lopen (litorale mosselbanken) en uit bodemmonsters (sublitoraal mosselbestand en litorale schelpdierbestanden) (figuur 5).

\section{Aangetroffen afval Waddenzee}

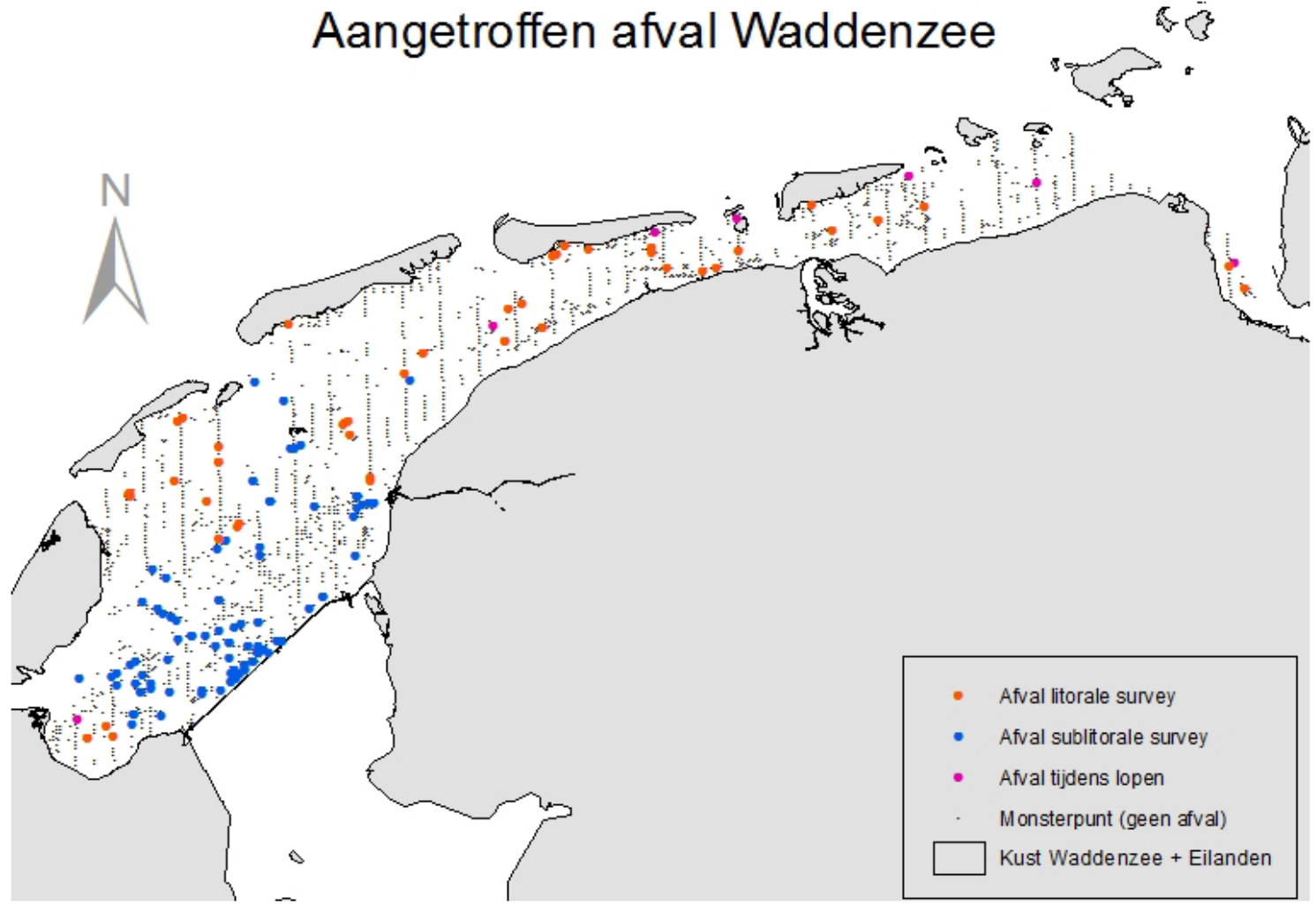

Figuur 5. Overzichtskaart aangetroffen afval tijdens de surveys in de Waddenzee (oranje = aangetroffen in bodemmonsters litorale survey, blauw = aangetroffen in bodemmonsters sublitorale survey, roze = aangetroffen tijdens lopen, zwart = geen afval aangetroffen).

In de Waddenzee is op 128 van de 1952 bemonsterde locaties afval gevonden. Het meest aangetroffen type afval was vispluis (116 stuks), gevolgd door visdraad (12 stuks). Het complete overzicht wordt gegeven in tabel 3. In bijlage 2 zijn twee kaarten met het aangetroffen aantal stuks afval per locatie en het totale gewicht van afval in grammen per locatie weergeven.

Er zijn 518 mossel- en oesterbanken ingelopen. Om een ruwe inschatting te maken van de totale afstand die lopend is afgelegd, is ten eerste de totale omtrek van alle ingelopen banken berekend, en is ten tweede per bank gemiddeld 1 kilometer aan extra reisafstand geschat. Samen komt dit neer op een totale afstand van tussen de 600 en $700 \mathrm{~km}$, verspreid over alle droogvallende wadplaten. Alle items die daarbij zijn aangetroffen, zijn opgesomd in tabel 3 en weergegeven in figuur 6 . 
Tabel 3. Aangetroffen soorten afval in aantallen en totaalgewicht in gram.

\section{Verzameld afval}

\begin{tabular}{l|cc|l|} 
Voorwerp & Aantal & Totaalgewicht (g) & Methode \\
\hline Vispluis & 116 & 12.6 & Bodemmonster \\
Visdraad & 12 & 13.2 & Bodemmonster \\
Touw & 11 & 12.1 & Bodemmonster \\
MZl gerelateerd & 5 & 0.1 & Bodemmonster \\
Plastic zak & 4 & 2.1 & Bodemmonster \\
Elastiek & 3 & 3.6 & Bodemmonster \\
Plastic verpakking & 3 & 1.2 & Bodemmonster \\
Voering, vulling kleding & 2 & 2.2 & Bodemmonster \\
Afgeknipte tiewrap & 1 & 1.3 & Bodemmonster \\
Binddraad vuilniszak & 1 & 0.0 & Bodemmonster \\
Folie & 1 & 0.0 & Bodemmonster \\
Glas & 1 & 9.8 & Bodemmonster \\
Glasvezel & 1 & 5.7 & Bodemmonster \\
Kous & 1 & 1.7 & Bodemmonster \\
Netwerk & 1 & 0.0 & Bodemmonster \\
Plastic beker & 1 & 0.2 & Bodemmonster \\
Tafelkleed & 1 & 0.4 & Bodemmonster \\
Schoenen & 4 & & Lopend \\
Mandje & 2 & & Lopend \\
Router-achterpaneel & 1 & & Lopend \\
Railing rugsteun & 1 & & Lopend \\
Ballon & 1 & & Lopend \\
Touw & 1 & & Lopend \\
& & &
\end{tabular}

*1 - Vispluis: ook wel pluis genoemd, fel oranje of blauwe plastic draadjes die in trossen onder visnetten voor bodemvisserij hangen om deze te beschermen tegen slijtage. (Bron: Vispluisvrij)

$* 2$ - Visdraad: Gekleurde of transparante plastic draad, afkomstig uit de sportvisserij. 


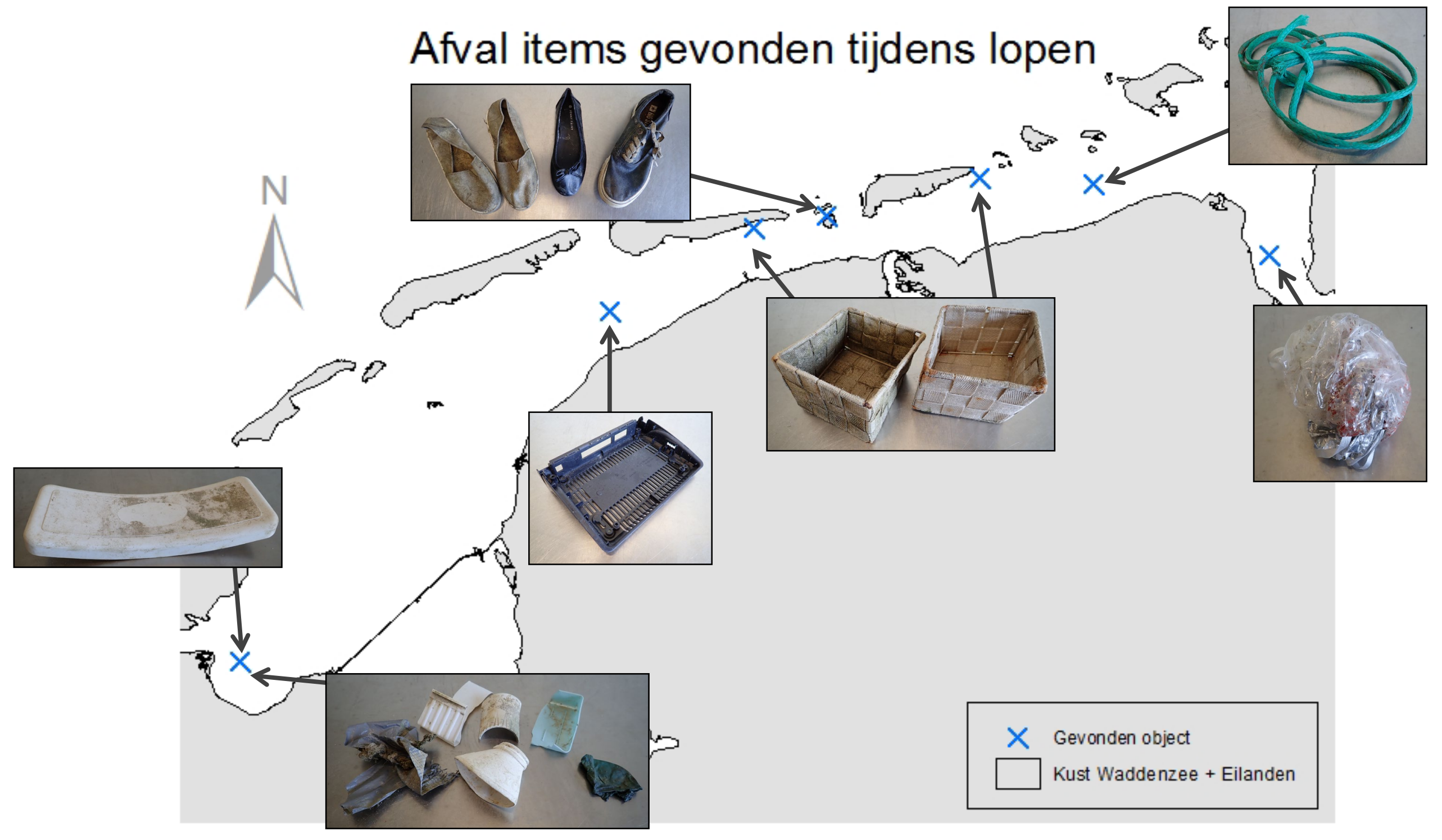




\section{$4 \quad$ Conclusies en discussie}

\section{Conclusie}

Tijdens de bemonsteringen in het kader van de reguliere schelpdiersurveys in de Nederlandse kustzone en de Waddenzee zijn geen afval items gevonden welke afkomstig waren uit de verloren containers van MSC Zoë. Tijdens het inlopen van mossel- en oesterbanken in de Waddenzee zijn op vier locaties in totaal 7 items gevonden welke mogelijk afkomstig waren uit de containers, en daarnaast op 3 locaties afval dat waarschijnlijk afkomstig was uit andere bronnen. Er kan gezegd worden dat de registratie van afval tijdens de schelpdiersurvey's een onderschatting geeft als dit vergeleken wordt met de hoeveelheden aangespoeld en opgevist afval.

\section{Discussie}

Veel van het afval dat uit de verloren containers in zee terecht is gekomen, is aangespoeld op de kusten van de Waddeneilanden en het vaste land. De vraag hoeveel er op de zeebodem terecht was gekomen, vormde de aanleiding voor de uitgevoerde afval registratie tijdens schelpdiersurveys.

Op de Noordzee en Waddenzee zijn vooral vispluis, visdraad, glas en overig (scheeps-) afval aangetroffen. Vermoedelijk is geen van deze items afkomstig uit de verloren containers. De betreffende items zijn in voorgaande jaren ook aangetroffen tijdens surveys (hoewel niet geregistreerd) en zijn waarschijnlijk tot zeker van overige scheepvaart afkomstig in plaats van uit de verloren containers. Dat er geen afval uit de containers is opgevist met de gebruikte monstertuigen betekent niet automatisch dat het er niet was. De monstertuigen zijn gericht op bemonstering van bodemfauna, niet op bemonstering van afval. Bepaalde items, met name items kleiner dan de maaswijdte van $5 \mathrm{~mm}$ of groter dan de opening van de monstertuigen, zijn mogelijk gemist. Afval dat boven de bodem in het water zweeft kan in theorie voor het monstertuig uit geduwd worden zonder dat het daadwerkelijk opgevist wordt. Dat er wel afval aanwezig was op de bodem of daar vlak boven wordt bevestigd door het feit dat kustvissers in de periode vanaf het incident tot nu (november 2019) nog steeds afval items aantreffen in hun netten. Daarnaast zijn er waarnemingen gedaan door hobby duikers rond wrakken in dit gebied, ook hier werden diverse objecten aangetroffen welke te relateren vielen aan de containerlading (NRC 2019). (Omrop fryslan, 20-08-2019; NRC, 15-09-2019; DDNZ; 15-09-2019).

Tijdens het inmeten van litorale mossel- en oesterbanken in de Waddenzee zijn op 7 locaties afval items aangetroffen. Op 4 van deze locaties, onder Ameland en Schiermonnikoog was het afval mogelijk afkomstig uit de verloren lading van de MSC Zoë. De items (4 schoenen, 2 mandjes en plastic router-achterpaneel (figuur 6)). Op de overige aangegeven 3 locaties leek een andere bron meer voor de hand liggend (rugsteun van een zeilboot, overige plastics zoals stukjes van koffiebekertjes, ballon en een stukje touw). Op een totaal van tussen de 600 en 700 afgelegde kilometers is dat niet veel. Daarnaast zijn geen opvallende waarnemingen gedaan tijdens het lopen, welke erop zouden kunnen wijzen dat tijdens de bemonsteringen veel afval is gemist. 


\section{$5 \quad$ Kwaliteitsborging}

Wageningen Marine Research beschikt over een ISO 9001:2015 gecertificeerd kwaliteitsmanagementsysteem. Dit certificaat is geldig tot 15 december 2021. De organisatie is gecertificeerd sinds 27 februari 2001. De certificering is uitgevoerd door DNV GL. 


\section{Literatuur}

Asch, M. van; Ende, D. van den; Pool, J. van der; Brummelhuis, E. B. M.; Zweeden, C. van; Es, Y. van; Troost, K. Het Kokkelbestand in De Nederlandse Kustwateren in 2019; Cvo Report, 19.009; Stichting Wageningen Research, Centrum voor Visserijonderzoek (CVO): IJmuiden, 2019.

NRC 2019 - https://www.nrc.nl/ nieuws/2019/09/15/2-500-kilo-afval-uit-de-noordzee-gehaalda3973408

Perdon, K.J., K. Troost, J. van Zwol, M. van Asch \& J. van der Pool. 2018. Schelpdierbestanden in de Nederlandse kustzone in 2018. CVO rapport: 18.010 .

Troost, K., M. van Asch, E. Brummelhuis, D. van den Ende, J. Jol, J. Perdon \& C. van Zweeden, 2016. Handboek bestandsopnames schelpdieren WOT. Versie2, mei 2016. Intern CVO rapport: 16.005.

Van den Ende, D., K. Troost, M. van Asch, J. Perdon \& C. van Zweeden. 2018. Mosselbanken en oesterbanken op droogvallende platen in de Nederlandse kustwateren in 2018: bestand en arealen. CVO rapport: 18.023 .

Van Stralen, M., D. van den Ende, K. Troost. 2019. Inventarisatie van het sublitorale wilde mosselbestand in de westelijke Waddenzee in het voorjaar van 2019. Rapport 2019.187 


\section{Verantwoording}

Rapport C122/19

Projectnummer: BO-43-023.02-039

Dit rapport is met grote zorgvuldigheid tot stand gekomen. De wetenschappelijke kwaliteit is intern getoetst door een collega-onderzoeker en het verantwoordelijk lid van het managementteam van Wageningen Marine Research

Akkoord:

Dr. J. Craeymeersch

Onderzoeker

Handtekening:

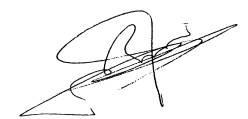

Datum:

06-12-2019

Akkoord:

Drs. J. Asjes

Manager Integratie

Handtekening:

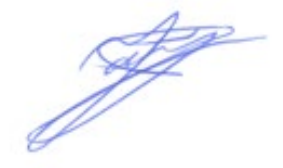

Datum:

06-12-2019 


\section{Bijlage 1 Overzichtskaarten Noordzee}

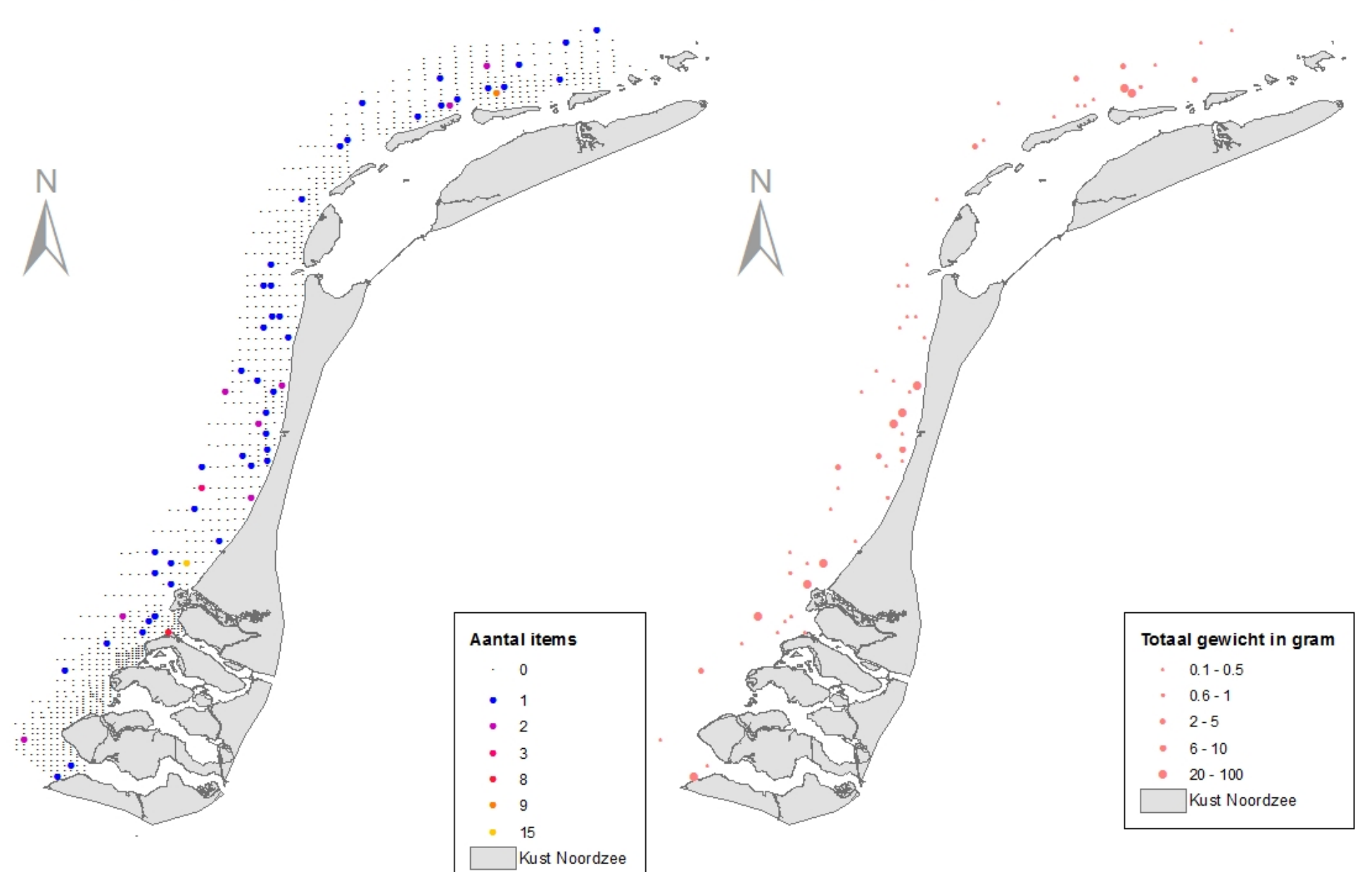

Figuur 7. Overzichtskaarten aangetroffen afval items Noordzee. Boven, afval in aantallen per monsterpunt, Onder totaal gewicht (gram) per monsterpunt 


\section{Bijlage 2 Overzichtskaarten Waddenzee}

Aantal afval items per monsterlocatie

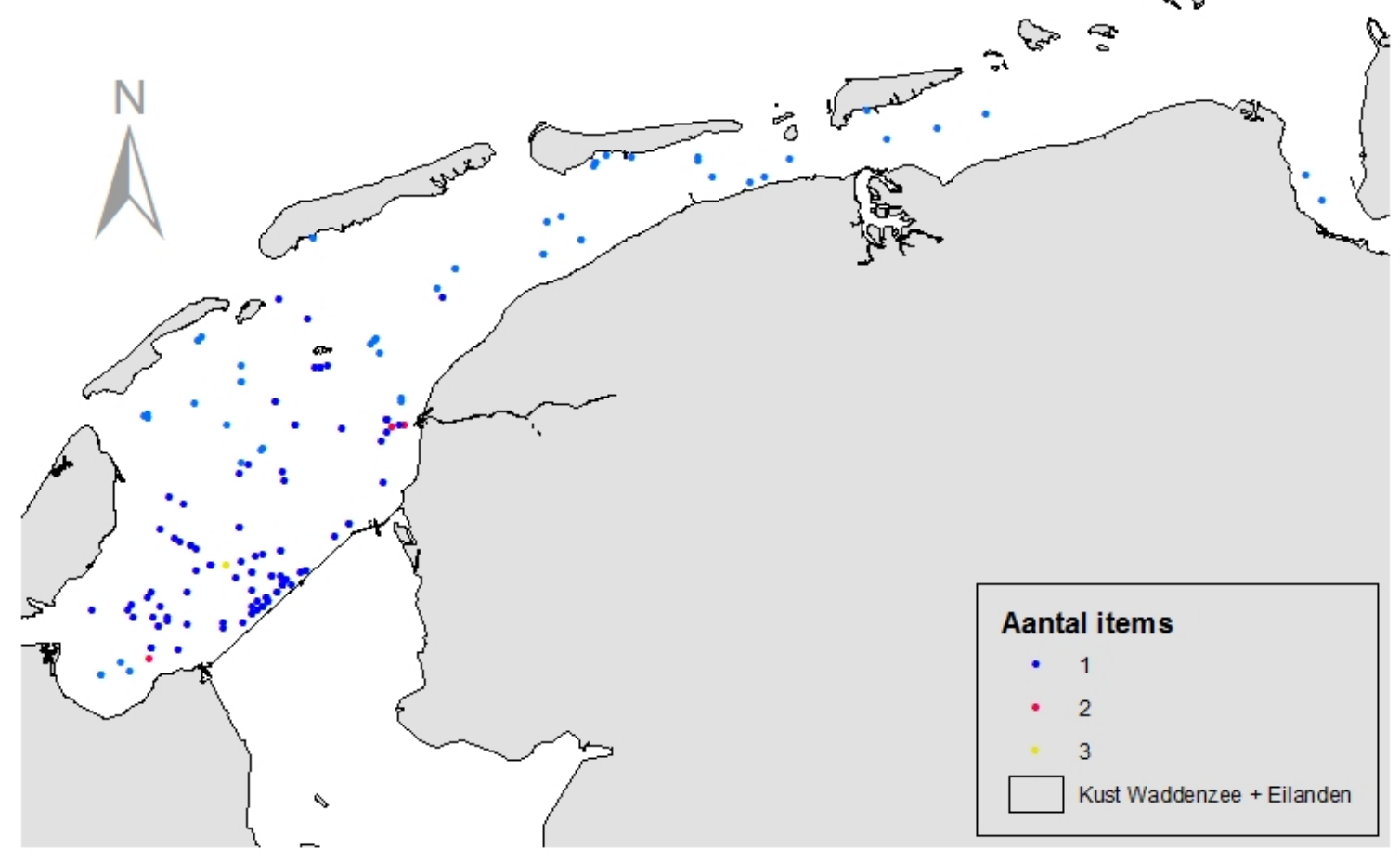

Totaal gewicht afval per monsterlocatie

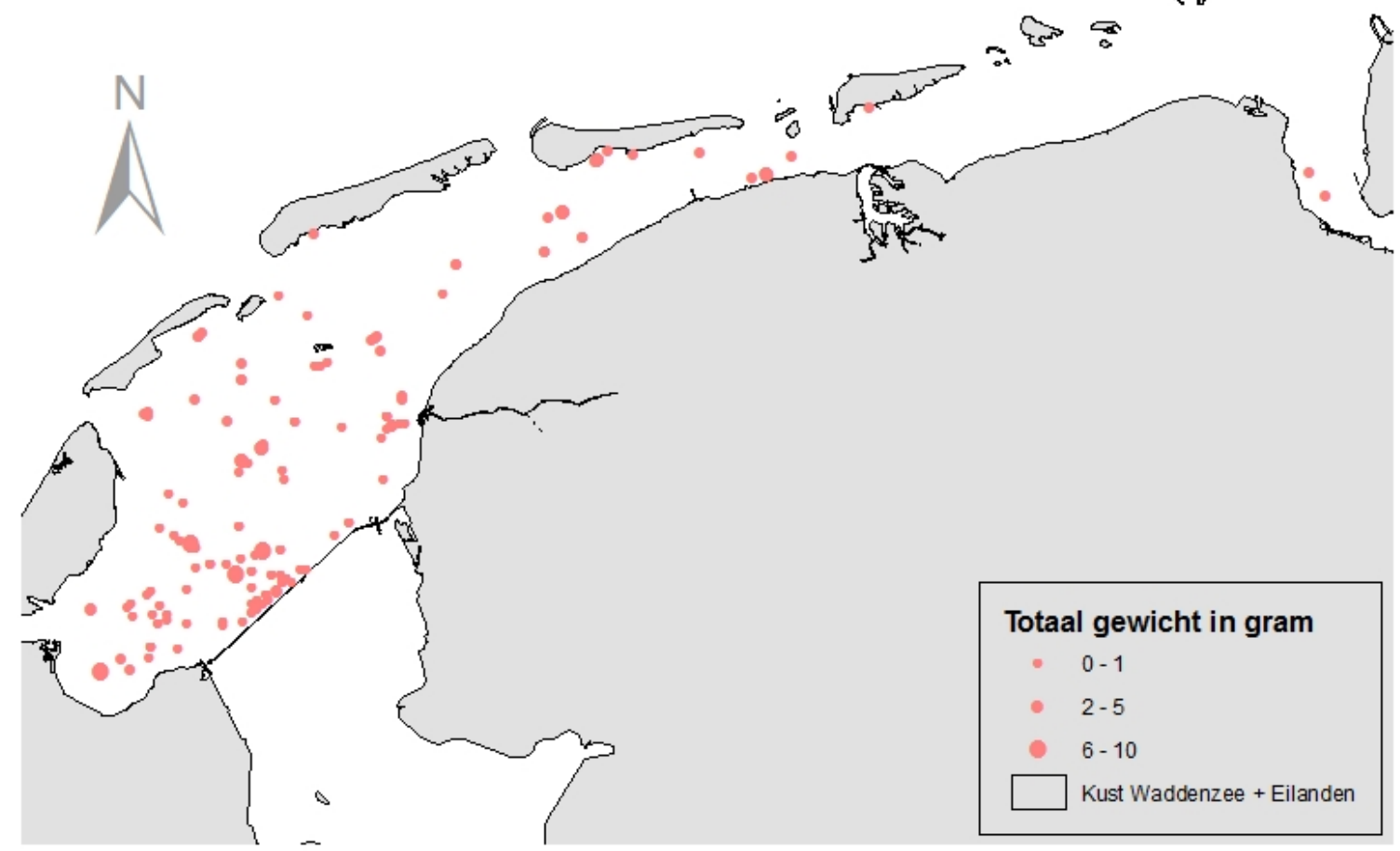

Figuur 8. Overzichtskaarten aangetroffen afval items Waddenzee. Boven, afval in aantallen per monsterpunt, Onder totaal gewicht (gram) per monsterpunt 


\section{Bijlage 3 Invoer overzicht IBTS}

\begin{tabular}{|c|c|c|c|}
\hline Litter overview & & & \\
\hline A: Plastic & B: Metals & & Related size category \\
\hline A1. Bottle & B1. Cans (food) & & $A:<5^{*} 5 \mathrm{~cm}=25 \mathrm{~cm}^{2}$ \\
\hline A2. Sheet & B2. Cans (beverage) & & $B:<10^{*} 10 \mathrm{~cm}=100 \mathrm{~cm}^{2}$ \\
\hline A3. Bag & B3. Fishing related & & $C:<20^{*} 20 \mathrm{~cm}=400 \mathrm{~cm}^{2}$ \\
\hline A4. Caps/ lids & B4. Drums & & $D: \angle 50 * 50 \mathrm{~cm}=2500 \mathrm{~cm}^{2}$ \\
\hline A5. Monofilament & B5. Appliances & & $E:<100 * 100 \mathrm{~cm}=10000 \mathrm{~cm}^{2}=1 \mathrm{~m}^{2}$ \\
\hline A6. Entangled filaments & B6. Car parts & & $\mathrm{F}:>100 * 100 \mathrm{~cm}=10000 \mathrm{~cm} 2=1 \mathrm{~m} 2$ \\
\hline A7. Synthetic rope & B7. Cables & & \\
\hline A8. Fishing net & B8. Other & & \\
\hline \multicolumn{4}{|l|}{ A9. Cable ties } \\
\hline \multicolumn{4}{|l|}{ A10. Strapping band } \\
\hline \multicolumn{4}{|l|}{ A11. Crates and containers } \\
\hline \multicolumn{4}{|l|}{ A12. Diapers } \\
\hline \multicolumn{4}{|c|}{ A13. Sanitary towel/tampon } \\
\hline \multicolumn{4}{|l|}{ A14. Other } \\
\hline C: Rubber & D: Glass/ Ceramics & E: Natural products & F: Miscellaneous \\
\hline C1. Boots & D1. Jar & E1. Wood (processed) & F1. Clothing/ rags \\
\hline C2. Balloons & D2. Bottle & E2. Rope & F2. Shoes \\
\hline C3. Bobbins (fishing) & D3. Piece & E3. Paper/ cardboard & F3. Other \\
\hline C4. Tyre & D4. Other & E4. Pallets & \\
\hline C5. Glove & & E5. Other & \\
\hline C6. Other & & & \\
\hline
\end{tabular}


Wageningen Marine Research

T: $+31(0) 317480900$

E: marine-research@wur.nl

www.wur.nl/marine-research

Bezoekers adres:

- Ankerpark 271781 AG Den Helder

- Korringaweg 7, 4401 NT Yerseke

- Haringkade 1, 1976 CP IJmuiden
Wageningen Marine Research levert met kennis, onafhankelijk wetenschappelijk onderzoek en advies een wezenlijke bijdrage aan een duurzamer, zorgvuldiger beheer, gebruik en bescherming van de natuurlijke rijkdommen in zee-, kust- en zoetwatergebieden.
Wageningen Marine Research is onderdeel van Wageningen University \& Research. Wageningen University \& Research is het samenwerkingsverband tussen Wageningen University en Stichting Wageningen Research en heeft als missie: 'To explore the potential of nature to improve the quality of life' 